\title{
COVID: The Second
}

\author{
Nandini Chatterjee
}

Bengal Physician Journal (2021): 10.5005/jp-journals-10070-7058

The second wave of coronavirus disease-2019 (COVID-19) stealthily crept upon us by the end of February 2021 as we let our guards down, thinking the worst was over. Though news of the surge of cases in the Europe and United States in late January was rampant, they seemed like far-off noises that we ignored.

The reasons for the second wave are manifold. ${ }^{1}$ Uncontrolled mass gatherings for religious, social, and political reasons continued in various corners of the country. Coupled with this were the poor risk perception and health literacy of our populace. Higher population density along with an upsurge of mutant strains of the virus that are more transmissible and pathogenic are the two most important factors responsible. The B.1.617 and B.1.618 strains with structural mutations in the spike proteins are said to be less affected by current vaccine responses. ${ }^{2}$ Air pollution in our cities where there is an increased concentration of small particulate matter leads to compromised lungs and more chances of COVID infection. ${ }^{3}$

The characteristics of the second wave seem to be somewhat different from the first wave. The younger healthy population is being increasingly affected in contrast to last years' predilection for the elderly and patients with comorbidity. Sudden deterioration in oxygen saturation and overwhelming spread in patients with supposed stronger immunity is a recurring pattern without adequate explanation. ${ }^{4}$

The decline in the first wave was gradual but it seems the second wave is demonstrating a sharp rise and fall in case counts within a period of 3 months. This may be attributable to vaccination drives or an increase in herd immunity.

A novel consequence of the second wave is the recognition of more post-COVID sequelae and opportunistic fungal infectionsthe most notorious being mucormycosis and aspergillosis. Rhinoorbitocerebral mucormycosis is reaching epidemic proportions in post-COVID diabetic patients and in those with prolonged or high-dose steroids or immunosuppressive therapy. Many states have declared it an epidemic as of June 2021. The COVID-associated mucormycosis (CAM) prevalence is around $0.27 \%$ in wards with a dismal prognosis and mortality of $40-50 \%$. COVID-associated pulmonary aspergillosis (CAPA) is also rearing its ugly head though less than CAM. ${ }^{5,6}$

The current scenario is overwhelming the healthcare infrastructure with a scarcity of beds, oxygen, and essential medicines. Horrific images of people gasping for breath in the roadside fill the television screens. People bid goodbyes from a distance as the wheelbarrows carry away their loved ones in
Department of Medicine, IPGMER/SSKM, Kolkata, West Bengal, India

Corresponding Author: Nandini Chatterjee, Department of Medicine, IPGMER/SSKM, Kolkata, West Bengal, India, Phone: +919830271571, e-mail: nandinibpj21@gmail.com

How to cite this article: Chatterjee N. COVID: The Second. Bengal Physician Journal 2021;8(2):33.

Source of support: Nil

Conflict of interest: None

zipped-up body bags. There is a cue in crematoriums and bodies rot in morgues or float in the rivers. Those who manage to survive often end up with various debilitating sequelae.

Despite all this, public memory is short-lived, and we forget the horrors and commit the same mistakes. Also the fatigue of lockdown and restrictions is setting in. It is important to spread the word that COVID-appropriate behavior is what we need to inculcate as a natural part of our lives. If the lessons learned from the second wave are to be remembered and caution is practiced in conjunction with vaccination, we can keep the third wave from spiraling out of control.

\section{References}

1. Cherian S, Potdar V, Jadhav $S$, et al. Convergent evolution of SARS-CoV-2 spike mutations, L452R, E484Q and P681R, in the second wave of COVID-19 in Maharashtra, India. bioRxiv 2021. DOI: 10.1101/2021.04.22.440932.

2. Sahoo JP, Mishra AP, Samal KC. Triple mutant Bengal strain (B.1.618) of coronavirus and the worst COVID outbreak in India. Available from: https://bioticainternational.com/ojs/index.php/biorestoday/article/ view/837. April 27, 2021.

3. Comunian S, Dongo D, Milani C, et al. Air pollution and COVID-19: the role of particulate matter in the spread and increase of COVID-19's morbidity and mortality. Int J Environ Res Public Health 2020;17(12):4487. DOI: 10.3390/ijerph17124487.

4. Jain VK, lyengar KP, Vaishya R. Differences between first wave and second wave of COVID-19 in India. Diabetes Metab Syndr 2021;15(3):1047-1048. DOI: 10.1016/j.dsx.2021.05.009.

5. Dyer O. Covid-19: India sees record deaths as "black fungus" spreads fear. BMJ 2021;373:n1238. DOI: 10.1136/bmj.n1238.

6. Sahoo JP, Panda B, Mishra AP, et al. The unseen "fungal infections"an extra thrust aggravating COVID second wave in India. Available from: https://bioticainternational.com/ojs/index.php/biorestoday/ article/view/877. May 24, 2021. 